\title{
GESTIÓN ESTATAL DEL SUELO URBANO. UN ANÁLISIS DE LA LUCHA SOCIAL POR EL ACCESO AL SUELO URBANO, EL MERCADO INFORMAL Y LA INTERUENCIÓN DEL ESTADO A PARTIR DEL CASO DE "LA RUBITA" DE RESISTENCIA, CHACO
}

\section{Silvina LÓPEZ / Venettia ROMAGNOLI}

Silvina López. Docente FAU-UNNE, coordinadora del área de Planificación en el marco del convenio IPDUV- Ministerio de Desarrollo Urbano y Territorial de la Provincia del Chaco. Email: silvina_lopez@hotmail.com.

Venettia Romagnoli. Docente investigadora IIDVi-FAU-UNNE. Becaria Doctoral CONICET y asesora técnica en el marco del convenio IPDUV- Ministerio de Desarrollo Urbano y Territorial de la Provincia del Chaco. Email: venettiaromagnoli@hotmail.com

Palabras Clave: Acceso al suelo urbano. Ocupaciones informales. Gestión del Estado. Keywords: : Access to urban soil, informal occupations, State management.

\section{RESUMEN}

Este trabajo se propone analizar una experiencia local de gestión del suelo urbano llevada adelante por el Estado provincial a partir del caso paradigmático del predio conocido popularmente como La Rubita, de propiedad original del Ejército Argentino y que ha sido objeto durante los últimos quince años de sucesivas ocupaciones informales por parte de demandantes de tierra, como así también de varias intervenciones de diversas gestiones gubernamentales. En 2010 el terreno fue adquirido por el Gobierno de la Provincia del Chaco, que encomendó al Programa Provincial de Planificación Física: Territorio Urbano del Instituto Provincial de Desarrollo Urbano y Vivienda (IPDUV) la formulación de proyecto urbano-habitacional.

\section{ABSTRACT}

This work proposes to analyze a local experience of urban soil taken forward by the provincial government from the paradigmatic case of the land known popularly as La Rubita, original property of the Argentine Army and that has been for the last fifteen years object of successive informal occupations by land claimants, as well as of several interventions of various governmental efforts. In 2010 the land was acquired by the Government of the Province of Chaco, who commissioned to the Provincial Physical Planning Program: Urban Territory, from the Provincial Institute of Urban Development and Housing, the formulation of urban housing project. 


\section{OBJETIVOS}

\section{Objetivo general}

Reflexionar acerca de una experiencia local de intervención del Estado para solucionar el acceso al suelo urbano de aquellos hogares que no tengan esta oportunidad a través del mercado ni de las políticas habitacionales vigentes, a partir de la toma de una chacra vacante ubicada en un área privilegiada de la ciudad de Resistencia de la provincia del Chaco conocida como "La Rubita".

\section{Objetivos particulares}

- Reconstruir el proceso de gestión de acceso al suelo urbano en el caso de "La Rubita", identificando los diversos actores involucrados (sociales, económicos, institucionales, políticos, etc.) y las acciones implementadas.

- Analizar el caso a la luz del marco interpretativo propuesto y señalar aciertos y desaciertos de la intervención del Estado de manera de extraer conclusiones que aporten a la construcción de políticas más adecuadas de acceso al suelo.

\section{INTRODUCCIÓN}

Este trabajo propone analizar el proceso de gestión de acceso al suelo en el caso de "La Rubita", entendiendo que este se constituye en una experiencia paradigmática en el contexto provincial, ya que en el trascurso de los últimos quince años ha sido objeto de sucesivas ocupaciones informales por parte de demandantes de tierra, como así de varias intervenciones de diversas gestiones gubernamentales. El predio de 84 ha, de propiedad original del Ejército Argentino y ocupado parcialmente por una población aproximada de mil familias ${ }^{1}$, fue adquirido en 2010 por el Gobierno de la Provincia del Chaco, que encomendó al Programa Territorio Urbano del IPDUV la formulación de proyecto urbano-habitacional.

[1 ] En el momento de formulación del proyecto la población era de 580 familias. Desde 2009 no s realizaron más censos oficiales.
A partir de la reconstrucción del proceso, la identificación de los diversos actores involucrados y de las acciones implementadas, se pretende señalar - a la luz del marco interpretativo propuesto- algunos aciertos y desaciertos de la intervención del Estado en pos de aportar a partir de la reflexión crítica a la construcción de políticas más acertadas y equitativas de acceso al suelo urbano.

El trabajo se desarrollará en cuatro apartados, el primero dedicado a explicitar el posicionamiento teórico desde el cual se analizará la experiencia; el segundo, a dar cuenta de las condiciones contextuales del problema del acceso de los pobres al suelo urbano a escala latinoamericana, argentina y del Área Metropolitana Gran Resistencia (AMGR). Posteriormente, en la sección tercera, se avanzará en la descripción del caso, para finalizar en una serie de reflexiones finales a partir del análisis de la experiencia a la luz del marco interpretativo propuesto.

\section{DESARROLLO}

\section{Posicionamiento teórico y marco interpretativo}

1.a. Concepción del problema del acceso al suelo de los pobres al suelo urbano y el rol del Estado

La tierra urbana vacante y las dificultades de acceso al suelo de la población pobre

Como regla general, la tierra vacante en Latinoamérica está a cargo de uno o más de los siguientes agentes (cada uno con sus políticas respectivas): gestores o subdivisores inmobiliarios (legales o ilegales); pequeños propietarios de tierras (incapacitadas para desarrollarlas); especuladores de bienes raíces, empresas estatalesy otras instituciones, como la Iglesia, el estado militar, etc. (CLICHEVSKY, 2005).

Muchas de estas áreas vacantes podrían soportar actividades residenciales o productivas en las que debería construirse una infraestructura urbana a fin de mejorar la eficiencia del uso de las tierras; no obstante, una cantidad considerable de ellas 
presenta una serie de factores negativos, como inadecuada infraestructura básica, agua contaminada por desechos industriales, riesgos naturales y vías de acceso deficientes. Esas parcelas no son aptas para ser urbanizadas, a menos que se realicen inversiones considerables que las resguarden de los citados problemas.

Por otro lado, el problema de acceso al suelo urbano por parte de la población pobre se constituye en un fenómeno de gran magnitud en Latinoamérica, que ha dado lugar a las ocupaciones ilegales con la finalidad de autosatisfacer las necesidades habitacionales de estos sectores. CASTELLS (1988) ha señalado que estos asentamientos asumen características particulares como una forma de movimiento social urbano con capacidad para reorientar la lógica urbana, específicamente en relación con la asignación de tierras, infraestructura y vivienda.

BENÍTEZ (2001) ha señalado que uno de los rasgos más peculiares de estos asentamientos originados en ocupaciones masivas es el de la organización de los ocupantes, no solo para la instalación en el terreno, sino fundamentalmente después, a efectos de impedir el desalojo, obtener algunos beneficios para el asentamiento, tales como la extensión de la red de agua, chapas de cartón, obtener la ley de expropiación y con ello la posterior regularización dominial y consolidación del asentamiento, demandar asistencia alimentaria o puestos de empleos en los programas sociales.

Los señalamientos de estos autores en relación con las características que asumen las ocupaciones informales de tierra y las estrategias de los actores para satisfacer sus necesidades sociohabitacionales fundamentan la necesidad de un abordaje integral. El problema específico de acceso al suelo que aborda este trabajo no puede verse de manera aislada respecto del resto de las dimensiones que afectan las condiciones de vida de los hogares en situación de pobreza, lo que nos lleva a abordar el problema desde la complejidad (BARRETO, 2009). Este enfoque implica concebir que el problema del ingreso económico de los hogares debe conside- rarse en relación con los otros elementos que hacen a las condiciones de vida de los hogares, y de los cuales estos pueden encontrarse excluidos, tales como la educación, la salud, la vivienda u otros problemas ambientales-territoriales, culturales, jurídicos y políticos, incluyéndose la percepción de los propios hogares sobre sus situación, ya que ellos, en sus particularidades y relaciones, inciden sobre el problema del ingreso de los hogares y sus posibilidades concretas de acceso al suelo.

La vivienda ocupa una posición central en las preocupaciones de los hogares y en sus condiciones de vida. Esto la hace un factor estratégico para iniciar una intervención integral del problema, y hace de esta política una acción estratégica del Estado para iniciar una reversión integral de la exclusión. A partir de este enfoque, se considera que el Estado debe asumir el compromiso de garantizar umbrales mínimos de satisfacción de las necesidades humanas básicas a todos aquellos hogares afectados por la exclusión, como vía de integración social.

Es aquí donde resulta ineludible plantear la estrecha vinculación entre las estrategias del Estado para dar respuesta al problema de acceso al hábitat digno por parte de las poblaciones pobres con la planificación urbana. BARRETO (2010) plantea que una política integral de villas y asentamientos debe contar entre sus líneas de acción con una componente de prevención, como un eje clave para frenar el crecimiento del problema. En este sentido, se entiende que resulta mucho menos costoso encausar procesos que se inician, que reparar acciones irregulares consolidadas. Sumado a esto, plantea que todo proceso físico debe estar acompañado de una componente de integración social, que comprende a todas las acciones sociales que se realizarán junto al mejoramiento físico del hábitat, para inducir el inicio de un proceso sostenido de reversión de los déficit de las dimensiones sociocultural, económica y política.

A partir de lo expuesto, se comparte con CLICHEVSKY (2009) que las políticas urbanas deberían 
prestar más atención a la tierra vacante considerando su diversidad de condiciones, y utilizarla para promover una mayor "racionalidad urbana" a fin de estimular la ocupación de lotes disponibles donde ya cuentan con infraestructura apropiada, suprimiendo el crecimiento urbano descontrolado. Una acción de esta medida requiere una mayor influencia del Estado en los mercados de tierras, en combinación con el establecimiento de programas de fortalecimiento institucional y creación de capacidades. Este involucramiento del Estado en sus distintos niveles jurisdiccionales implica, además, que la administración del suelo urbano vacante se realice en función de la planificación urbana general de cada ciudad y del reconocimiento del derecho de los pobres de acceder a suelo urbano de calidad.

Por otro lado, la gestión estatal del suelo no puede realizarse sin un marco normativo adecuado que incluya la definición de estrategias e instrumentos que permitan, entre otras cosas, la recuperación de plusvalía, el control de la expansión urbana y el desaliento a la retención de tierras por parte de grandes terratenientes.

Se entiende, además, que uno de los instrumentos que puede utilizar el Estado para gerenciar el suelo urbano vacante son los proyectos urbanos integrales, ya que pueden impulsar cambios urbanos inmediatos capaces de afectar los valores del suelo $y$, en consecuencia, su uso, y refuncionalizar ciertas áreas de la ciudad (LUNGO Y SMOLKA, 2005).

Para el análisis del caso de la Rubita -entendiendo que el mismo fue objeto, como se verá más adelante, de la formulación de un proyecto urbano integral-, se toman tres puntos básicos que los proyectos deberían considerar, propuestos por LUNGO Y SMOLKA (2005):

a) la capacidad institucional de gerenciar el proceso del proyecto de acuerdo con la complejidad y la escala de este;

b) la vinculación del proyecto con el Plan de la Ciudad, entendiendo que la ejecución de grandes proyectos urbanos puede estimular el plan gene- ral, contribuir a modificarlo o propiciar su formulación si no existiera. En todo caso, el manejo del suelo resulta un factor esencial tanto para el plan como para los proyectos, porque remite al punto crítico del marco normativo sobre los usos del suelo en la ciudad y su área de expansión, y

c) la vinculación con el marco normativo: la solución normativa preferida sería una intervención bipartita, que mantuviera una normativa general para toda la ciudad modificando los criterios convencionales para que puedan tener flexibilidad y absorber los incesantes cambios que ocurren en los ámbitos urbanos y permitir normativas específicas para determinados proyectos, pero evitando marcos normativos que puedan ir contracorriente de los objetivos planteados en el Plan de Ciudad. También resulta destacable el rol dinamizador de este tipo de proyectos para la revisión de la normativa o la formulación de esta en los casos en que no existiera.

\section{Marco contextual}

2.1. El acceso al suelo urbano de las poblaciones en situación de pobreza: la situación de América Latina, Argentina, Chaco y Área Metropolitana Gran Resistencia (AMGR):

América Latina: las condiciones de pobreza de $\mathrm{AL}$ y el Caribe y el funcionamiento del mercado legal de tierras han restringido - a lo largo de los rápidos procesos de urbanización de los países de la región- las posibilidades de la población de acceder a vivir en determinadas áreas urbanas. El acceso de manera legal al suelo urbano para los pobres es reducido en la historia de nuestras ciudades, condenándolos a vivir en diferentes tipos de hábitat informales (CLICHEVSKY, 2006).

En relación con la informalidad, algunos autores han señalado que este fenómeno tiene su origen en el funcionamiento de un mercado legal con determinadas condiciones en la oferta de suelo, precios y financiamiento, que hacen imposible su acceso a un sector importante de la población urbana, en un contexto de pobreza y precariedad 
laboral (LUNGO, 1989; JARAMILLO, 1987; CLICHEVSKY, 1975). Actualmente en AL la población que vive en condiciones de informalidad en relación con el suelo urbano llega a aproximadamente al $40 \%$ en muchas ciudades y áreas metropolitanas (CLICHEVSKY, 2006).

El mercado de tierras (tanto formal como informal) ha sido escasamente regulado por el Estado en los países de la región; tanto es así que la mayoría de las políticas estatales implementadas en Latinoamérica se han circunscripto a actuar sobre los procesos de informalidad ya iniciados, más que a prevenirlos. Las políticas de prevención han sido prácticamente nulas. En este contexto, la población pobre se ha visto obligada a recurrir a dos formas fundamentales de informalidad urbana: la ocupación directa y el mercado ilegal (ambos fenómenos - como se verá más adelante- se dan en el caso de La Rubita).

Argentina y el caso del Área Metropolitana Gran Resistencia: en el caso de Argentina, la problemática habitacional de las "villas" y "asentamientos" comenzó a tomar formas similares a las actuales a mediados del siglo XX en las principales ciudades del país. ${ }^{2}$ Sin embargo, en las últimas décadas, este fenómeno comenzó a afectar también a las ciudades intermedias, como consecuencia de las trasformaciones estructurales de la producción agraria, que han generado expulsión de poblaciones rurales tradicionales hacia las ciudades del interior del país (BARRETO Y OTROS, 2014). Las intervenciones del Estado en la problemática habitacional urbana también tienen una larga historia en el país, aunque nunca se aplicó una política específica estructural para estos sectores sociales más excluidos de la sociedad. Fue recién en los años 90 -en el marco de las políticas neoliberales de ajustes estructurales- cuando surgió una serie de programas (mejoramiento de barrios, lotes con servicios, etc.), orientados de manera focalizada a los hogares en situación de pobreza, residentes en villas y

[2 ] Surgió en relación directa con el incremento de las migraciones rurales provocadas por la incipiente industrialización y el crecimiento del intercambio comercial que trajo aparejado el denominado "proceso de sustitución de importaciones". asentamientos, con objetivos vinculados más con la contención que con la transformación del problema (ROMAGNOLI, 2011).

Posteriormente, a partir de 2008, en un contexto de recuperación del rol del Estado, comenzó a elaborarse un proyecto de "Ley Nacional de Ordenamiento Territorial para el Desarrollo Sustentable", que aún se encuentra en discusión en distintos ámbitos gubernamentales y de la sociedad civil, y que podría tener impacto en cuestiones muy sensibles para la política de vivienda, como el tema de la prevalencia del interés social del suelo por sobre el de los particulares.

En este contexto, la situación del AMGR —donde se localiza el caso de estudio- resulta paradigmática por la complejidad que asume el problema como consecuencia de la interrelación de una serie de factores que se desarrollarán a continuación. Se trata de un área metropolitana intermedia compuesta por cuatro municipios (Resistencia, Barranqueras, Fontana y Puerto Vilelas), que sufrió desde mediados del siglo XX un acelerado crecimiento poblacional sin que mediara un desarrollo socioeconómico y productivo paralelo. De acuerdo con MAGNANO (2005), este crecimiento poblacional del AMGR (que concentra casi el $40 \%$ de la población provincial, y de acuerdo con las proyecciones cuenta aproximadamente en la actualidad con más de 430.000 habitantes) se ha venido concretando sobre un territorio con importantes restricciones físico-ambientales, por tratarse de un territorio altamente vulnerable en el valle natural de inundación de los ríos Negro y Paraná ${ }^{3}$ (PILAR, 2003). Esta situación determinó la necesidad de la construcción de un sistema de defensas.

Históricamente, la urbanización no tuvo en cuenta los accidentes naturales (rellenando sectores bajos sin readecuación de las pendientes generales de escurrimiento), y redujo los espejos de agua del sistema lacustre del río Negro, lo que sumado a las defensas construidas, afectó la capacidad de reservorio y el drenaje natural del territorio.

[3 ] El $80 \%$ de su superficie se encuentra por debajo de los niveles alcanzados en crecientes históricas (PILAR: 2003) 
Figura 1. Plano del AMGR. Asentamientos informales en suelos públicos (nacionales, provinciales y municipales) y privados existentes en 2008. Fuentes: elaboración propia. SIG del IIDVI, PICTO UNNE 200700100 sobre la base de fuentes del Programa Territorio Urbano y el IPDUV, del gobierno de la provincia del Chaco

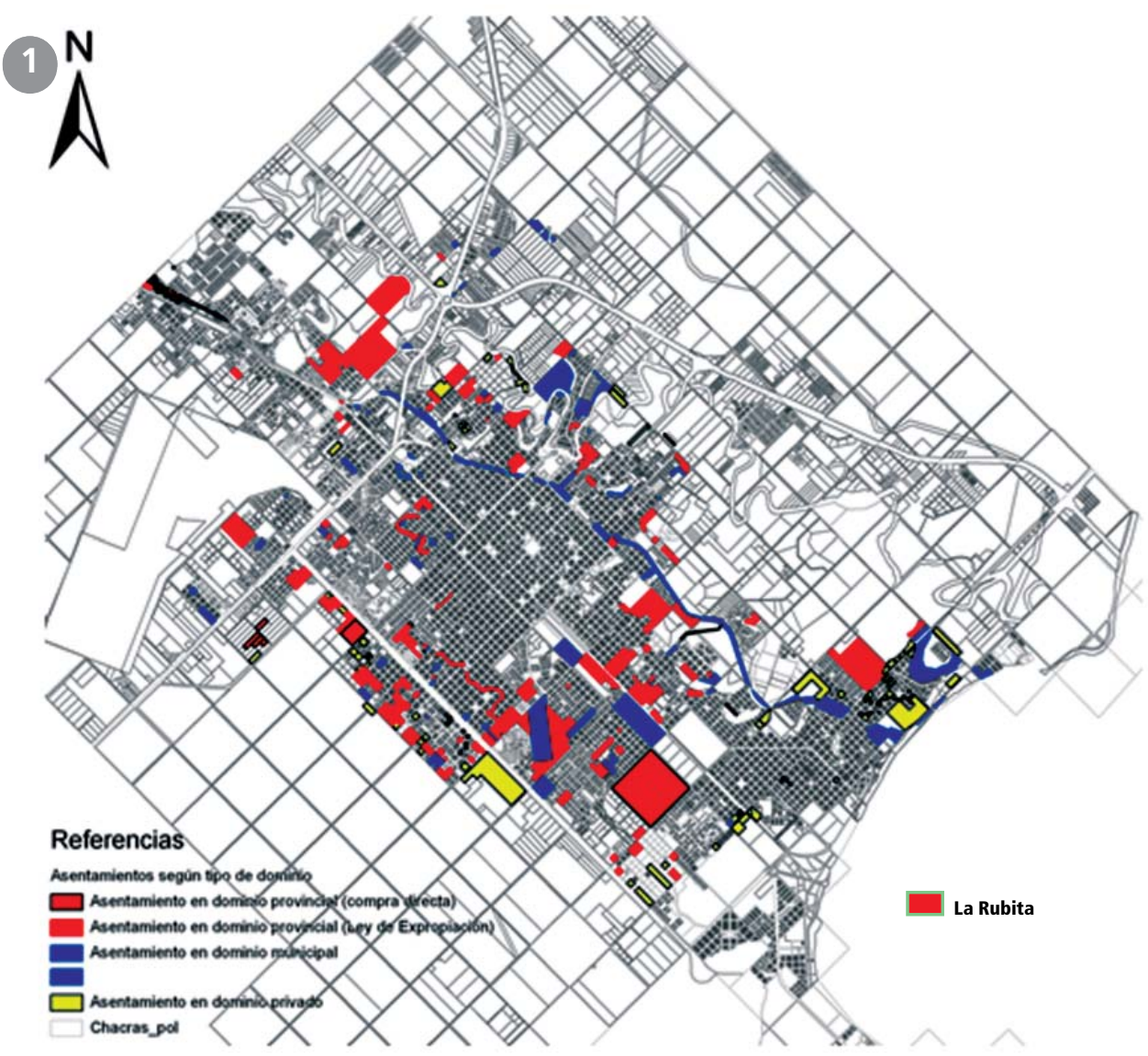

La situación ambiental descripta combinada con la ausencia de planificación física, la vigencia de normas urbanas poco flexibles ${ }^{4}$, el predominio de los fuertes intereses particulares (sector inmobiliario y de las empresas constructoras contratistas de obras del Estado) que se beneficiaron con el crecimiento de la ciudad y de una adecuada política preventiva de acceso al suelo restringieron la oferta de terrenos accesibles para las poblaciones pobres. Esta demanda insatisfecha desencadenó la ocupación informal de tierras públicas y privadas. Actualmente en el AMGR existen aproximadamente 270 villas $\mathrm{y}$ asentamientos informales que cuentan con una población estimada de entre 100.000 y 130.000 habitantes (20 a $30 \%$ de la población). (1.Figura 1. Plano del AMGR. Asentamientos informales en suelos públicos (nacionales, provinciales y municipales) y privados existentes en 2008)

Otro de los factores que complejizan el problema es el tipo de configuración urbana que se ha ido consolidando como consecuencia de la ausencia de reservas de tierra para la política habitacional por parte del Estado provincial y municipal, lo que generó que las localizaciones de los conjuntos habitacionales dependieran exclusivamente de la oferta privada y del manejo del valor del suelo que

[4] El Código de Planeamiento Urbano Ambiental de la ciudad de Resistencia (Ley N.․ 2406), que data del año 1979, no ha sido objeto de una actualización integral. realiza el mercado inmobiliario, determinando localizaciones cada vez más alejadas y con menores dotaciones de infraestructuras, servicios, accesibilidad, etc. De acuerdo con BARRETO, LÓPEZ y ROMAGNOLI (2011), como resultado de las discontinuidades naturales del territorio ya descritas y de las características de la urbanización residencial (baja densidad, viviendas en lotes individuales en conjuntos aislados), la ciudad tuvo un crecimiento extensivo, discontinuo y disperso. ${ }^{5}$ La producción de nuevos barrios, sin el acompañamiento de la apertura de calles y de la urbanización de los espacios vacantes intermedios, generó un espacio urbano fragmentado, sin conectividad básica y con serios problemas de accesibilidad.

En este contexto, la adquisición de importantes reservas de tierra urbana de propiedad original del Ejército Argentino por parte del Estado provincial (entre ellas 41 chacras del Ex Campo de Tiro y 84 hectáreas La Rubita) se constituye en una oportunidad inédita para la formulación de políticas de prevención de asentamientos. El caso que se analizará a continuación es un ejemplo que permite examinar el rol y posicionamiento del Estado en el manejo y gestión de la tierra urbana vacante.

[5] De acuerdo con un diagnóstico de BARRETO (2013), en el AMGR hay un 20 a un $30 \%$ de tierra vacante ociosa en la zona urbana. 


\section{El Caso de La Rubita}

El predio está localizado en el sudeste del ejido de Resistencia (Chacra 284), limitado por las Av. CasteIli, Av. Arribálzaga, Sarmiento y la Av. Edison, en el límite con el municipio de Barranqueras. Este predio formaba parte de las instalaciones del Ejército Argentino y antiguamente estuvo identificado de acuerdo con la zonificación del Código de Planeamiento Urbano Ambiental de Resistencia como distrito E6: "equipamiento determinado, terrenos de grandes dimensiones que están ocupados por un equipamiento específico". El terreno fue utilizado para la provisión de suelo usado en la construcción del terraplén de defensa contra las inundaciones del AMGR (construido a partir de 1983), lo que generó profundas "cavas" y depresiones en el predio.

\subsection{Primeras ocupaciones y proyectos}

El 16 de marzo de 1997 se produjo la ocupación de La Rubita por parte de casi quinientas familias, que en pocas horas armaron sus viviendas provisorias y permanecieron en el lugar por una semana, hasta que fueron desalojadas por fuerzas de Gendarmería Nacional, como consecuencia de un pedido que gestionó el Ejército Nacional ante la Justicia Federal. En el breve período que duró la ocupación, se pusieron en marcha toda clase de mecanismos jurídicos y políticos que dieron al caso gran repercusión social y política. Los ocupantes sostenían que la ocupación fue espontánea, a diferencia del juez federal y el gobierno provincial, que insistían en la hipótesis de la toma organizada y sobre todo "instigada con fines políticos", tal como lo señalaron algunos involucrados directos.

"Usurpación es cuando yo violento una puerta, salto un alambre, volteo una pared para entrar en tal lugar. De esas dos cosas no nos pudieron comprobar porque no existieron. No había pared ni alambre, nada que nos detenga, la tierra estaba abierta. Y la instigación si bien es cierto que hubo una pequeña instigación de parte de los dirigentes, los demás se sumaron así nomás. Una vez que hizo alguien de cabecera, los demás te siguen. Por naturaleza el necesitado viene y agarra (...)" (dirigente social, 2011).

“(...) en ese entonces en el año 97 éramos 1700 familias, después quedamos 400 familias hasta el final a soportar, y eso fue lo que dio origen a la Asociación Civil La Rubita, (...)"6 (dirigente social, 2011).

Tras el desalojo de las familias ocupantes de La Rubita, muchos dejaron el lugar inmediatamente y otros siguieron reclamando esas tierras. Posteriormente, en el año 1999, en el marco de un Convenio de Cooperación Técnica entre el Programa Arraigo de la Nación y la Municipalidad de Resistencia, se elaboró una propuesta de ordenamiento urbano ambiental para la chacra 284 (La Rubita) y la chacra 277 del área sur de la ciudad, también de propiedad del Ejército Argentino, incorporándolas al uso urbano mediante un proyecto (aprobado por la Ordenanza N. ${ }^{\circ} 4206$ del año 1999). Es así que el área cuenta con una normativa particular que establece usos del suelo predominantemente residenciales, con distritos (R4, R5), de baja densidad y subzonas rurales (ZR4) para la localización de pequeños productores, además del equipamiento de uso local. A pesar de haber sido aprobada, la propuesta para el predio nunca se materializó, y durante los años posteriores se produjeron nuevas ocupaciones, subdivisiones irregulares y construcciones precarias, sin que se concrete ninguna intervención oficial para consolidar el área. En el dinámico proceso de expansión urbana, quedó rodeada de áreas residenciales con distintos niveles de consolidación y conjuntos habitacionales construidos por operatorias oficiales.

\subsection{Ocupaciones y proyectos más recientes}

En octubre de 2007 se produce una nueva toma de La Rubita liderada por las mismas organizaciones que habían sido desalojadas en 1997. 
Figura 2. Imágenes de viviendas construidas los días posteriores a la toma. Fuente: Organización "Eucaliptus". 2008

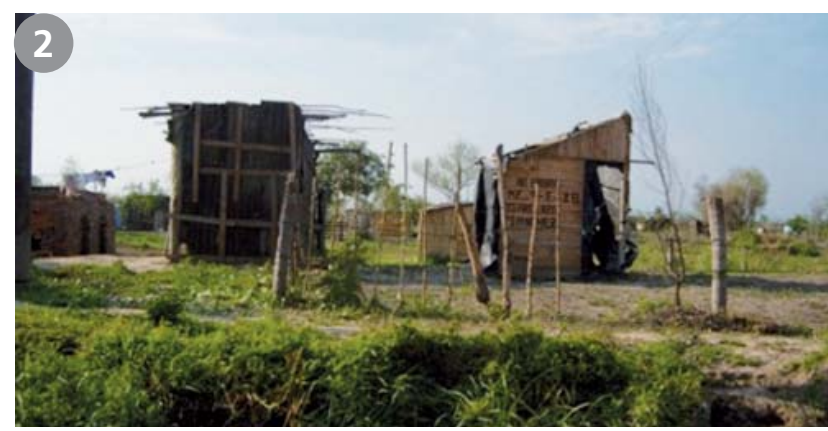

en el 2007 volvemos a tomar La Rubita, con ese miedo que se tomó en el 97. Por eso ustedes van a ver que en la toma del 2007 éramos menos, unos cuarenta compañeros que quedamos encauzados por instigación y usurpación del 97 (...) se cerró el caso, pero no sabíamos. En 2007 cuando entramos ahí nos enteramos que el caso ya había sido juzgado, siete años atrás. (...)"7 (dirigente social, 2011).

La ocupación fue realizada por alrededor de quinientas familias en grupos organizados que ocuparon el perímetro del predio y los sectores más altos, y demarcaron lotes regulares, dejando libres los espacios para la continuidad de las calles del entorno. Posteriormente, se sumaron familias que se fueron ubicando en forma más espontánea y desordenada. (2. Figura 2. Imágenes de viviendas construidas los días posteriores a la toma).

Según el relevamiento realizado ${ }^{8}$, se pudieron obtener datos acerca de la población que participó de la toma. Las familias eran oriundas del AMGR, mayoritariamente de Resistencia (65\%), en menor proporción de Barranqueras y Puerto Vilelas (23 y $12 \%$, respectivamente). En relación con la situación habitacional, el $82 \%$ de las personas se encontraba en ese momento compartiendo las viviendas con familiares, el $8 \%$ en viviendas prestada y el $8 \%$ en viviendas alquiladas.

En relación con la gestión del suelo, en abril de 2008 el Tribunal de Tasación de la Nación realizó la tasación de los terrenos de La Rubita, en cumplimiento del convenio firmado oportunamente entre el Gobierno de la provincia y el Ministerio de Defensa. En junio de 2008, con la rúbrica de un acta de intención entre el Gobierno del Chaco y el Ejército Argentino, comenzó el proceso de transferencia a la provincia de los inmuebles militares declarados innecesarios, entre ellos, La Rubita. Las parcelas que integran la Chacra 284, Secc. D, Circ. II, fueron adquiridas por Decreto 2116/08 del Gobierno de la Provincia del Chaco con la finalidad de sanear la situación dominial y social de los asentamientos.
Figura 3: Cantidad de familias por organización social. Fuente: Programa Territorio Urbano. 2008

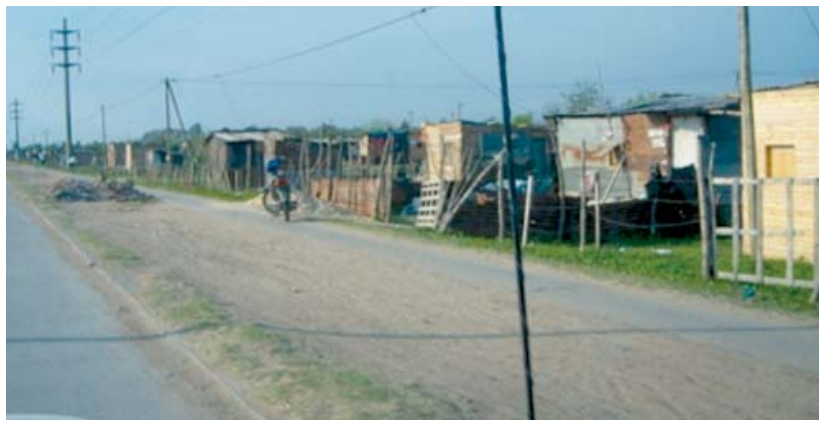

\begin{tabular}{|l|c|}
\hline ORGANIZACIONES & FAMILIAS \\
\hline Organización Civil Los Eucaliptus & 214 \\
\hline Unidad Asociativa Territorial de Base- UATB Casas del Sur & 370 \\
\hline $\begin{array}{l}\text { Unidad Asociativa Territorial de Base- UATB Madres sin } \\
\text { techo }\end{array}$ & 263 \\
\hline $\begin{array}{l}\text { Unidad Asociativa Territorial de Base- UATB Madres Plaza } \\
\text { de Mayo }\end{array}$ & 266 \\
\hline $\begin{array}{l}\text { Unidad Asociativa Territorial de Base- UATB Fortaleza } \\
\text { Urbana }\end{array}$ & 145 \\
\hline Organización No Gubernamental ONG La familia & 49 \\
\hline TOTAL & 1307 \\
\hline
\end{tabular}

\section{2.a. El proyecto de intervención en La Rubita}

EI IPDUV, a través del Programa Territorio Urbano PTU $^{9}$, tomó a su cargo la elaboración del proyecto con los siguientes objetivos: a) respetar y consolidar los hogares y organizaciones sociales que gestionaron el predio como lugar de vida; b) crear un área residencial de diferentes densidades y tipologías edilicias, previendo soluciones habitacionales para distintos sectores sociales ${ }^{10}$, y c) resolver el proyecto urbano de manera participativa y concertada con los grupos de demandas y con los condicionamientos formulados por la financiación de la oferta, mediante una mesa de acuerdos interactorales.

La organización de los ocupantes y la demanda: el primer registro de familias realizado en inicios de 2008 incluyó a aquellas que realizaron la toma, las que se instalaron posteriormente y las que reclamaban soluciones habitacionales en el predio. Las familias se nuclearon en seis organizaciones sociales con el objetivo de ser censadas por el gobierno y reconocidas en su situación de "ocupantes" para lograr asistencia para la construcción de viviendas y la provisión de servicios de agua y energía eléctrica, y de ser reconocidas como "beneficiarias" en los casos de aquellas que no se habían asentado pero que se constituían en demandantes de soluciones habitacionales en el predio. Los referentes de dichas organizaciones presentaron al PTU las listas y la documentación solicitada para su registro, como

[9] Este programa fue creado en 2008 por Decreto del Poder Ejecutivo N. ${ }^{\circ} 386$ en el inicio de su gestión de gobierno.

[10 ] Otras organizaciones sociales, entidades intermedias, consorcios y hogares individuales empadronados en el IPDUV. 
Figura 4. Imágenes de actividades de la Mesa de Gestión Fuente: Programa Territorio Urbano. 2009

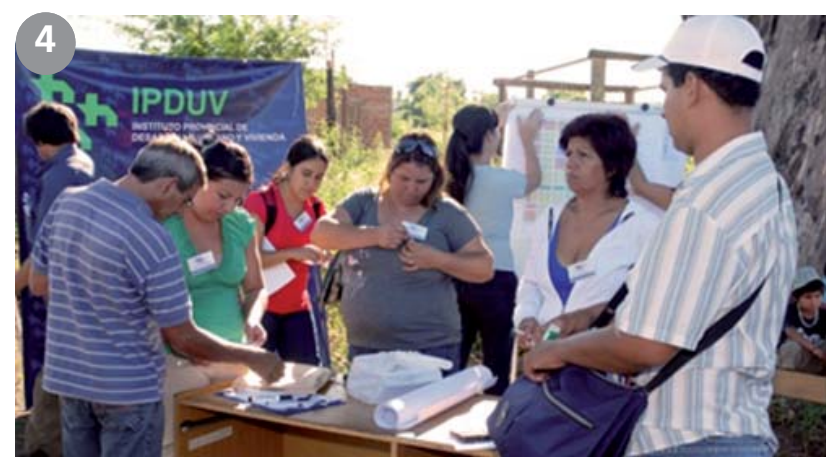

se puede ver en el siguiente cuadro. (3. Figura 3: Cantidad de familias por organización social).

El equipo de proyecto del PTU propuso la conformación de una mesa de gestión de La Rubita, integrada por técnicos interdisciplinarios de diferentes organismos provinciales, a la que se incorporaron en 2008 representantes de las organizaciones sociales mencionadas y con posterioridad otras tres organizaciones. ${ }^{11}$ Si bien comenzó a funcionar informalmente, en febrero de 2009 se incorporó el uso del Libro de Actas, en el que se asentaban las reuniones y las decisiones que se tomaban por consenso y votación. Inicialmente los temas tratados se referían a conflictos en el territorio y demandas de asistencia del Estado con la intención de lograr la consolidación de la ocupación.

Esto generó varias modificaciones en la constitución de la mesa, incluyendo la expulsión de miembros de algunas organizaciones.

Posteriormente, cuando el equipo de proyecto trabajó sobre la situación física del predio, en cuanto a su vulnerabilidad hídrico-ambiental y la necesidad de inversiones estructurales en infraestructu$\mathrm{ra}$, y a partir de una concepción sustentada en la necesidad de un proyecto integral y sustentable, se acordó con las organizaciones el desarrollo de un proyecto de urbanización, que no solo diera respuestas a sus necesidades, sino que incluyera a otros demandantes de tierra y vivienda de diferentes sectores sociales.

Las actividades realizadas por este equipo de proyecto, tanto en el territorio como a nivel de gestión interinstitucional, fueron acompañadas por los referentes que conformaron la mesa. (Figura 4. Imágenes de actividades de la Mesa de Gestión).

La relación con la Municipalidad y otros organismos del Estado: el equipo de proyecto hizo varios intentos de integrar el Municipio de Resistencia a

[11 ] UATB Vivir mejor, Org. “No al gatillo fácil” y MTD 17 de julio.

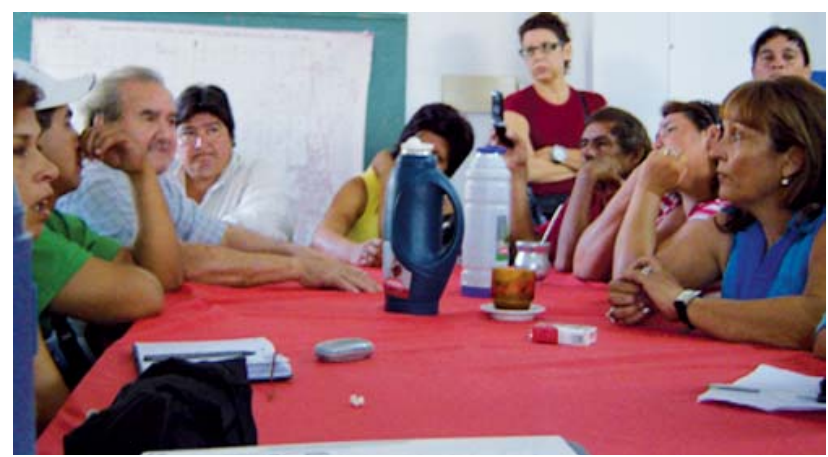

la mesa, ya que la escala del área para intervenir y la necesidad de modificar la normativa urbana adecuándola a los nuevos usos así lo requerían. Por otra parte, el mayor desafío del proyecto era la rehabilitación ambiental del predio, cuestión de imposible resolución sin la inclusión de toda la cuenca urbana, ${ }^{12}$ de la que el predio forma parte. Si bien desde la etapa de ideas preliminares el proyecto fue presentado al equipo de Planificación del Municipio, este se mantuvo en su rol de supervisor ajustándose al procedimiento y a la exigencia de los requerimientos establecidos en la carpeta de consulta (factibilidades hídricas, de infraestructura y servicios, etc.).

Como se señaló, el problema más grave del predio es la vulnerabilidad hídrico-ambiental ocasionada por las áreas bajas y las cavas artificialmente producidas, por lo que la Administración Provincial del Agua condicionó la intervención a la elaboración de los proyectos de infraestructura necesarios, cuya complejidad excedían las incumbencias y capacidades del equipo de proyecto. Por otra parte, la relación con las empresas prestadoras de servicios (SAMEEP y SECHEEP) fue complicada desde el inicio, ya que las familias asentadas presionaban constantemente por la conexión de los servicios. Al poco tiempo se implementaron conexiones y "tarifas sociales", que aceleraron la consolidación de las viviendas.

Posteriormente, debido a eventos pluviales, se produjo el anegamiento de sectores del predio dejando bajo agua a una gran cantidad de viviendas, lo que generó la evacuación, los reclamos y las respuestas asistenciales de las áreas de acción social, que en muchos casos aportaron equipos de materiales para mejorar las viviendas, y del Municipio, que realizó algunas obras de apertura de calles y zanjeo para mejorar el escurrimiento.

El proyecto del Programa Sueños Compartidos, de la Fundación Madres de Plaza de Mayo ${ }^{13}$ : en mar-

[12 ] Un área de aproximadamente 500 ha.

[13 ] Este programa, promovido por la Fundación Madres de Plaza de Mayo con distintas organizaciones sociales, fue lanzado con el objetivo de generar fuentes de trabajo, formalidad laboral y viviendas dignas para trabajadores desocupados y sus familias. 
Figura 5. Propuesta de usos del suelo y soluciones habitacionales. Fuente: proyecto Urbano La Rubita. Programa Territorio Urbano. 2009

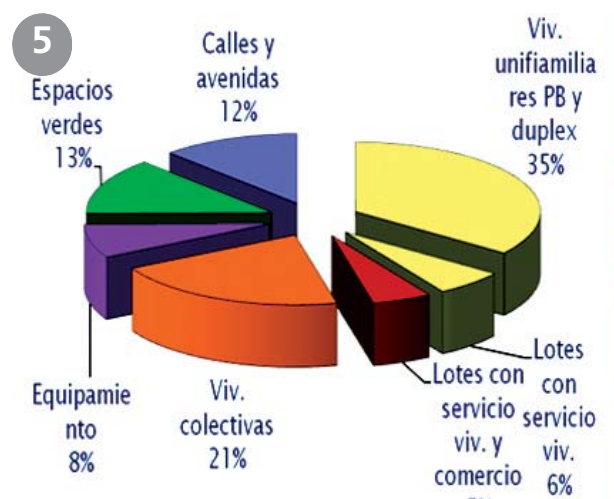

$5 \%$

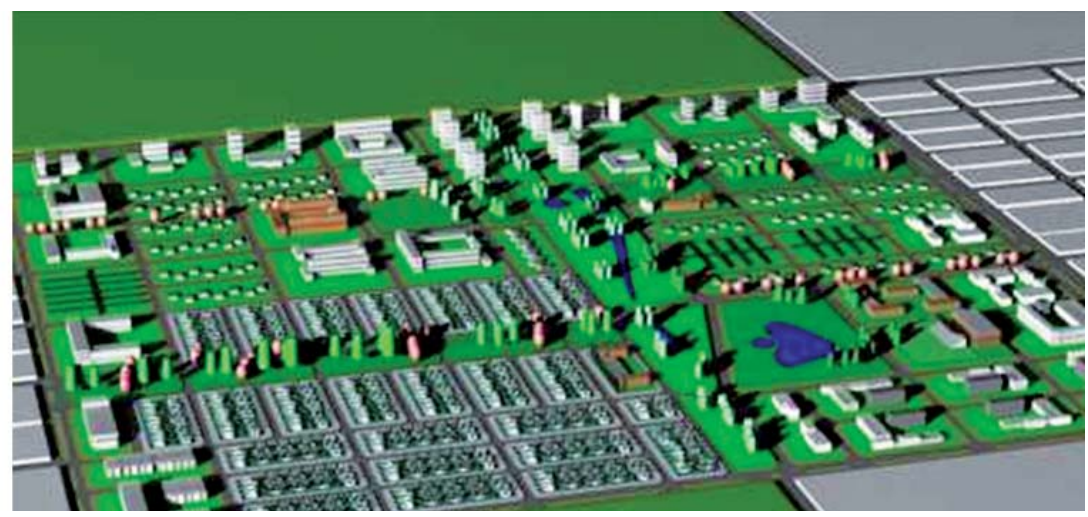

zo de 2008 el gobernador anunció que quinientas viviendas del Programa Sueños Compartidos se construirían en La Rubita.

El equipo técnico del programa trabajó en articulación con el equipo del PTU en la definición de la localización del conjunto habitacional y el proyecto de loteo, así como del sector en donde comenzaría la primera etapa de construcción de setenta viviendas. En el período de construcción, la inspección de la obra fue asignada a la Unidad Ejecutora de Proyectos Especiales del Ministerio de Infraestructura, Obras y Servicios Públicos, la que finalmente se hizo cargo de todas las cuestiones relacionadas con el proyecto, desvinculándose del equipo del PTU.

Las organizaciones que componían la mesa fueron incorporadas a este proyecto y comenzaron a trabajar activamente con la fundación, debilitando su vinculación a la Mesa de Gestión del Proyecto.

Formulación del proyecto urbano integral: a pesar de estos condicionantes y limitaciones, fue desarrollado el proyecto urbano que proponía para el predio un área de desarrollo urbano integral, que incorporaba conjuntos habitacionales de distintas densidades para diferentes sectores sociales, con sus correspondientes infraestructuras y equipamientos, con los objetivos de consolidar el área, propiciar la densificación y diversificación poblacional y funcional y disminuir el déficit de equipamientos y la fuerte dependencia del centro de la ciudad.

El proyecto planteó además la continuidad de los principales ejes y cruces urbanos, integrando las tramas de las ciudades de Resistencia y Barranqueras, reforzando la articulación metropolitana.

La escala del proyecto permitía generar una nueva centralidad con equipamientos a escala urbana, que se localizarían sobre los ejes principales, con importante superficie de espacios verdes debido a los déficits del entorno y a la topografía del predio. (5. Fig. 5. Propuesta de usos del suelo y soluciones habitacionales).

Los proyectos y obras estructurales de infraestructuras necesarios para urbanizar el predio representaban una inversión tal, que debió plantearse un proyecto de 3150 soluciones habitacionales, entre lotes con servicios, viviendas construidas por operatorias FONAVI, Planes Federales, cooperativas, gremios y asociaciones civiles y otros, tanto en soluciones individuales como colectivas, para que el proyecto fuese sustentable. El costo de la urbanización se estimó en $\$ 35.410 .000,00$ (mayo 2009) incluyendo en este monto la mensura, obras de saneamiento y relleno y las infraestructuras básicas. Esta inversión representaba el $13 \%$ del monto del proyecto completo, y el $15 \%$ considerando el valor que la provincia pagó por el terreno.

El proyecto urbano se presentó en Audiencia Pública en mayo de 2009, poniéndose a consideración de la comunidad y siendo aprobado por los organismos involucrados en los proyectos. En junio de 2009 se realizó un relevamiento físico para actualizar el estado de ocupación del predio, con el objetivo de realizar los ajustes necesarios al proyecto urbano.

El relevamiento se realizó con técnicos del PTU acompañados por los referentes designados por la Mesa de Gestión, sobre la base de planos construidos con imágenes satelitales.

Se realizó el registro de las viviendas, niveles de consolidación, cantidad de familias y antigüedad de la ocupación. Se pudo comprobar que si bien no había aumentado significativamente el número de familias, sí lo había hecho la cantidad de viviendas, muchas de las cuales se encontraban en proceso de construcción, sin ser todavía habitadas. Más del $70 \%$ de las viviendas fueron registradas como 
Figura 6. Superposición del proyecto con imagen satelital. Fuente: Programa Territorio Urbano. 2009

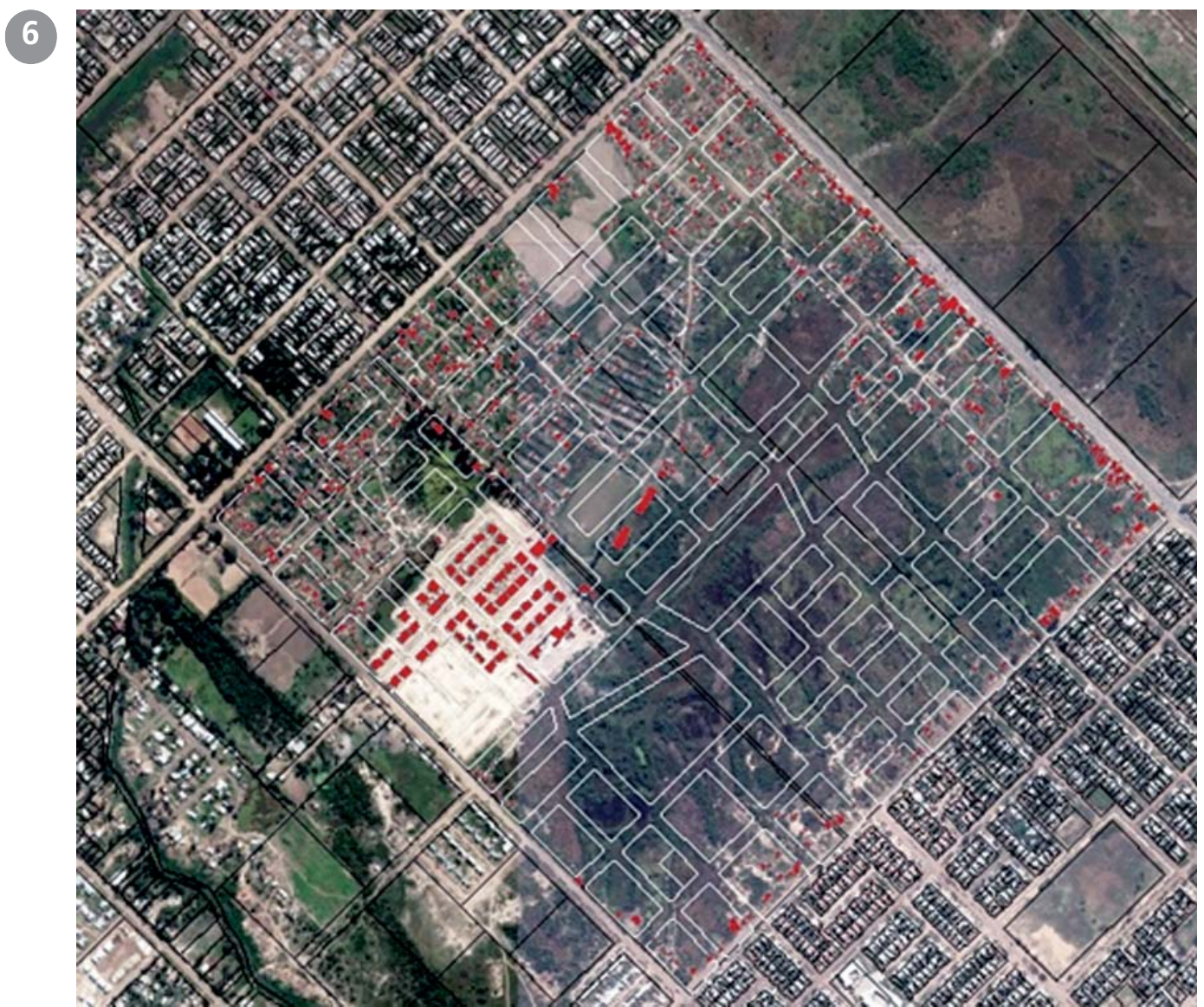

precarias, pero se observó que las construcciones más recientes tenían mayor nivel de consolidación. (6. Figura 6. Superposición del proyecto con imagen satelital).

La situación a fines de 2011: en cuanto a la aprobación del proyecto en el Municipio, nunca se superó la etapa de la carpeta de consulta, por lo que no se pudo consolidar el proyecto urbano con la mensura correspondiente $y$, en consecuencia, no se pudieron transferir los predios destinados a equipamientos a los respectivos organismos de salud, educación, seguridad, etc. para iniciar el proceso de gestión de la construcción, así como la red vial y los espacios verdes al municipio.

En relación con los proyectos de infraestructura, continúa en gestión en la Subsecretaría de Desarrollo Urbano y Vivienda de la Nación el financiamiento de las obras pluviales que incluyen la previsión de un cuenco (laguna) que actuará como reservorio de las aguas de lluvias, desde donde desaguar el predio hacia el sistema de drenaje urbano. En cuanto a los proyectos de viviendas, la primera etapa del conjunto de viviendas del proyecto Sueños Compartidos inició su ejecución sin la aprobación del Municipio, lo que generó numerosos conflictos, paralizaciones de obra, etc., y las viviendas no podrían ser ocupadas por no estar construidos los nexos a las infraestructuras. Los referentes de las organizaciones sociales fueron contratados por la fundación para la ejecución de ese proyecto, participando en los cupos de obreros que contratar y en la definición de prioridades de adjudicación de las viviendas.

En marzo de 2011, el gobernador del Chaco entregó las primeras setenta viviendas de Sueños Compartidos en La Rubita, estando prevista una segunda etapa de ciento dos viviendas.

En julio de 2011, ante el conflicto generado a nivel nacional por las supuestas irregularidades en el manejo de fondos públicos por la Fundación Madres de Plaza de Mayo, un grupo de 184 trabajadores del programa de viviendas tomaron el predio en el que trabajaban en reclamo de indemnizaciones y para que se les garantice la continuidad laboral con la nueva empresa que continuaría las obras. En este contexto, el gobierno provincial tomó a su cargo el proyecto, que sería licitado a partir de 2012.

La movilidad de ocupantes y la inmobiliaria informal: en el tiempo transcurrido, muchos de los ocupantes pusieron en venta los terrenos en valores que al principio variaban entre los 500 y los 
"(...) a quien le toque actuar, es una vergüenza ver en lo que se ha convertido el predio que era del Ejército, actualmente de los sin techo de La Rubita se ha convertido en una inmobiliaria. Toda la avenida llena de carteles de venta de terrenos, ¿quién les otorgó los títulos?".

tres mil pesos, dependiendo de la ubicación, pero que han ido creciendo, y en la actualidad se ofertan terrenos por valores que superan los 100.000 pesos. Los loteos irregulares se convirtieron en un negocio inmobiliario que inclusive se promociona en los diarios locales. La Av. Castelli, a lo largo de las ocho cuadras que van desde la Av. Arribálzaga hasta la Av. España, en poco tiempo fue convirtiéndose en una zona comercial que despliega una amplia variedad de rubros. La gratuidad de los servicios públicos de agua potable y energía eléctrica es resaltada por los vendedores como uno de los principales beneficios, principalmente en el caso de la instalación de locales comerciales. Tales situaciones han despertado diferentes manifestaciones y reclamos de la opinión pública.

"(...) a quien le toque actuar, es una vergüenza ver en lo que se ha convertido el predio que era del Ejército, actualmente de los sin techo de La Rubita se ha convertido en una inmobiliaria. Toda la avenida llena de carteles de venta de terrenos, ¿quién les otorgó los títulos?"

"(...) por este medio quiero dar a conocer algo que toda la ciudadanía sabe, la venta de terrenos en La Rubita...no tiene límites, desde ochenta y cinco mil pesos hasta ciento treinta mil, este predio está destinado para aquellas familias que no tiene donde vivir, pero se ha convertido en una inmobiliaria"14

\section{REFLEXIONES FINALES}

Retomando las tres variables de análisis propuestas por LUNGO Y SMOLKA (2005), y a la luz del caso de La Rubita precedentemente descrito, pueden hacerse algunas consideraciones. En primer lugar, en relación con la capacidad institucional para gerenciar el proyecto, y entendiendo que las necesidades habitacionales de los hogares en si-

[14 ] Página Web de Noticiero 9. Noviembre de 2011. tuación de pobreza no pueden verse de manera aislada al resto de sus condiciones de vida, por lo que requieren un abordaje integral, cabe señalar que ante la complejidad y la escala de La Rubita, hubiera sido deseable la conformación de una unidad de gestión del proyecto capaz de articular las intervenciones sectoriales del Estado. Como pudo observarse en el proceso descrito, si bien se realizaron trabajos conjuntos con algunas instituciones y organismos de otras áreas y niveles de gobierno, estos fueron circunstanciales, limitándose a resolver cuestiones coyunturales, sin consolidarse en el tiempo como modalidad de intervención.

Desde el punto de vista de la organización institucional para el abordaje del problema, al no estar definidas con claridad las competencias jurisdiccionales y los marcos normativos, la articulación del Estado en sus diferentes niveles en pos de propiciar intervenciones más integrales con base en la complementaridad de acciones resultó obstaculizada. Esta situación generó que los ocupantes y demandantes de tierra participen activamente del mercado informal de tierras, frente a un Estado incapaz de conducir y canalizar estos procesos, tal como se ha visto en La Rubita. El mismo hecho de la adquisición de la tierra por parte del gobierno provincial generó más ocupaciones y especulaciones en relación con el predio, ante la posibilidad de una tenencia más concreta.

Más positiva resultó la inclusión de las organizaciones sociales en el proyecto, por parte del equipo de proyecto del PTU y la creación de la Mesa de Gestión, que permitió el trabajo conjunto de los técnicos con los representantes de dichas organizaciones en la elaboración de un proyecto integral. Sin embargo, la escasa capacidad del Estado de consolidar estos procesos y la cooptación por parte de la Fundación Madres produjeron un empoderamiento negativo de algunos referentes, generando una apropiación por parte de estos actores de 
la Mesa de Gestión como forma de organización eficiente, pero dejando de lado los objetivos iniciales de concertación para los que fue concebida. Estos hechos se evidencian en el desplazamiento de los técnicos y de varias organizaciones que participaban legítimamente de aquella.

En relación con la vinculación del proyecto al Plan de la Ciudad, resulta criticable que el Municipio, como responsable jurisdiccional de este tipo de proyectos, no haya cumplido con su rol de manera activa, no atendiendo las cuestiones de políticas de tierras vacantes (consolidación de áreas, generación de instrumentos modernos de gestión del suelo, recuperación de plusvalías, etc.) ni participando activamente de los proyectos de gran envergadura, como es el caso de La Rubita, limitándose a un rol de contralor administrativo. De acuerdo con los señalamientos de varios autores, los proyectos de esta escala en tierras urbanas vacantes representan una oportunidad para la promoción de planes urbanos generales, en los casos en que no existieran o que requiriesen su revisión o actualización, como es el caso de la ciudad de Resistencia y su área metropolitana, cuyo "Plan de Ordenamiento Ambiental del Gran Resistencia y su área Metropolitana"15 data del año 1977, y si bien ha sido modificado por ordenanzas parciales, no fue objeto de una revisión integral. En este sentido, el caso de La Rubita — por su localización estratégica y la escala de su intervención- se constituye en la pérdida de una oportunidad significativa para avanzar en esta dirección.

En cuanto a la vinculación del proyecto con el marco normativo, si bien se pondera de manera positiva la intencionalidad del equipo formulador de plantear un proyecto urbano habitacional integral, que contemple las soluciones habitacionales, las infraestructuras y equipamientos necesarios, que incorpore a diferentes sectores demandantes de tierra urbana, como asociaciones intermedias, gremios, hogares individuales inscriptos en el IPDUV, demanda libre, etc., al no ser incluidos estos actores desde los inicios en el modelo de gestión y en la mesa conformada, esta intencionalidad no pudo plasmarse en hechos concretos. Uno de los problemas que pudo haber ocasionado esta dificultad recae en el hecho de la inexistencia de instrumentos normativos que enmarquen las asociaciones público-privadas para encarar proyectos de esta envergadura, como son, por ejemplo, los consorcios de urbanización, que permiten la conformación de alianzas estratégicas entre el municipio y agentes sociales para ejecutar proyectos urbanos y promover urbanización de áreas sin infraestructura.

A pesar de los conflictos de intereses que se han descrito, de las especulaciones, del incremento del mercado informal, del empoderamiento negativo de algunas de las organizaciones sociales intervinientes, etc., estas reflexiones corresponden a una etapa de un proceso que todavía no ha finalizado, y que podría llegar reencauzarse, implementando al menos algunas cuestiones planteadas en el proyecto, como así otras, algunas de las cuales fueron identificadas en este análisis. 


\section{BIBLIOGRAFÍA}

BARRETO, Miguel A.; ALCALÁ, Laura; BENÍTEZ, M. Andrea; FERNÁNDEZ M. Emilia; GIRÓ, Marta; PELLI, M. Bernabela Y ROMAGNOLI, Venettia (2014). La política Federal de Vivienda desde su implementación en el Gran Resistencia (2003- 2007). Análisis y Recomendaciones. Diseño, Buenos Aires, Argentina.

BARRETO, Miguel A.; LÓPEZ, Silvina y ROMAGNOLI, Venettia (2011). Estrategias de ordenamiento y desarrollo de las localidades urbanas de la Provincia del Chaco. Comunicaciones Científicas y Tecnológicas Anuales 2011. EDIFAU. Resistencia, Chaco.

BARRETO, Miguel A. (2010). El "hábitat digno" como meta de una política integral de áreas urbanas deficitarias críticas, para la integración social desde los derechos humanos. En: Revista INVI N. ${ }^{\circ}$ 69, Volumen 25, Páginas: 161-187. Edición: Instituto de la Vivienda, Facultad de Arquitectura y Urbanismo, Universidad de Chile, Santiago.

CLICHEVSKY, Nora (2006). Regularizando la informalidad del suelo en América Latina y el Caribe. Una evaluación sobre la base de 13 países y 71 programas. Serie Manuales N. ${ }^{\circ}$ 50. CEPAL. División de Desarrollo Sostenible y Asentamientos Humanos, Santiago de Chile.

CLICHEVSKY, Nora (2005). La tierra vacante en América Latina. Land Lines: January 1999, Volume 11, Number 1. Ed. LILP. Disponible en http://www. lincolninst.edu/pubs/pub-detail.asp?id=380.

CASTELLS, M. 1988. Crisis Urbana, Estado y Participación Popular. Colegio de Arquitectos de Cochabamba. Bolivia.

BENÍTEZ, María Andrea (2002). movimientos sociales y expansión urbana: las ocupaciones de tierra en la ciudad de resistencia (Arg.). En Cuaderno Urbano N. ${ }^{\circ}$ 3. Edición Forurbano. Resistencia, Chaco. Disponible en http://arq.unne.edu.ar/publicaciones/cuaderno_urbano/cu_3/index.html.

LUNGO, M. y SMOLKA, M. (2005). Suelo y grandes proyectos urbanos: la experiencia latinoamericana. En: Smolka, M. y Mullahy, L. 2007. Perspectivas Urbanas: Temas críticos en políticas de suelo en América Latina. Cambridge, MA: Lincoln Institute of Land Policy.

MAGNANO, María Cristina (2005). El suelo urbano y los Asentamientos informales en el Gran Resistencia. Chaco, Argentina. En revista INVI N. ${ }^{\circ}$ 54 / agosto 2005 / VOL. 20. Santiago de Chile.

ROMAGNOLI, Venettia (2011). "Pautas para la optimización de Programas de Mejoramiento Barrial. Un estudio sobre sus fundamentos teóricos y experiencias en el AMGR -Chaco (Argentina)". ISBN: 978-3-8443-4838-5. Editorial Académica Española, Berlín (Alemania). (Pág. 185). 